\title{
Fused eco29kIR- and $M$ genes coding for a fully functional hybrid polypeptide as a model of molecular evolution of restriction-modification systems
}

\author{
Marina L Mokrishcheva ${ }^{1,2}$, Alexander S Solonin ${ }^{1}$, Dmitri V Nikitin ${ }^{1 *}$
}

\begin{abstract}
Background: The discovery of restriction endonucleases and modification DNA methyltransferases, key instruments of genetic engineering, opened a new era of molecular biology through development of the recombinant DNA technology. Today, the number of potential proteins assigned to type II restriction enzymes alone is beyond 6000, which probably reflects the high diversity of evolutionary pathways. Here we present experimental evidence that a new type IIC restriction and modification enzymes carrying both activities in a single polypeptide could result from fusion of the appropriate genes from preexisting bipartite restriction-modification systems.

Results: Fusion of eco29kIR and M ORFs gave a novel gene encoding for a fully functional hybrid polypeptide that carried both restriction endonuclease and DNA methyltransferase activities. It has been placed into a subclass of type II restriction and modification enzymes - type IIC. Its MTase activity, 80\% that of the M.Eco29kl enzyme, remained almost unchanged, while its REase activity decreased by three times, concurrently with changed reaction optima, which presumably can be caused by increased steric hindrance in interaction with the substrate. In vitro the enzyme preferentially cuts DNA, with only a low level of DNA modification detected. In vivo new RMS can provide a $10^{2}$-fold less protection of host cells against phage invasion.

Conclusions: We propose a molecular mechanism of appearing of type IIC restriction-modification and M.Ssollrelated enzymes, as well as other multifunctional proteins. As shown, gene fusion could play an important role in evolution of restriction-modification systems and be responsible for the enzyme subclass interconversion. Based on the proposed approach, hundreds of new type IIC enzymes can be generated using head-to-tail oriented type I, II, and III restriction and modification genes. These bifunctional polypeptides can serve a basis for enzymes with altered recognition specificities. Lastly, this study demonstrates that protein fusion may change biochemical properties of the involved enzymes, thus giving a starting point for their further evolutionary divergence.
\end{abstract}

\section{Background}

DNA restriction-modification systems (RMS) are prokaryotic tools against invasion of foreign DNAs into cells [1]. They play an important evolutionary role as subcellular barriers restricting horizontal gene transfer and thereby providing microbial biodiversity. Usually, RMS comprise of a restriction endonuclease (REase) and

\footnotetext{
* Correspondence: dvnikitin@rambler.ru

${ }^{1}$ Institute of Biochemistry and Physiology of Microorganisms, Russian Academy of Sciences, Prospekt Nauki, 5, Pushchino, Moscow region 142290, Russia

Full list of author information is available at the end of the article
}

modification DNA methyltransferase (MTase) enzyme recognizing the same short 4-8 nucleotide sequence. RMS functioning includes methylation of recognition DNA sequences by MTase. All non-modified sites can be cut by a cognate REase [1]. Type II REases are indispensable tools in creating recombinant DNA molecules [2]. Their widespread practical application has stimulated research to discover and characterize more of these systems. Currently, more than 6000 different sequences corresponding to REases of type II alone are listed in REBASE, the database holding all known and many putative RMS [3].

\section{Ciomed Central}

(c) 2011 Mokrishcheva et al; licensee BioMed Central Ltd. This is an Open Access article distributed under the terms of the Creative Commons Attribution License (http://creativecommons.org/licenses/by/2.0), which permits unrestricted use, distribution, and reproduction in any medium, provided the original work is properly cited. 
The high number of known RMS is reflected also in high diversity of their organization or functioning and, hypothetically, in multiplicity of their evolutionary pathways. One of these pathways could be fusion of preexisting ORFs with formation of a gene capable of producing a protein with an array of new activities and functions. It could be suggested that type IIC RMS carrying both REase and MTase in a single polypeptide might appear by this mechanism [4]. Here we report direct evidence how a fully functional type IIC REase could appear by fusion of the appropriate genes as a result of a few point mutations.

As an object of our experiment Eco29kI RMS was chosen. This RMS is carried by the natural plasmid pECO29 found in clinical E. coli $29 \mathrm{kI}$ isolate [5]. On this plasmid there were genes coding for 214 aa REase and 382 aa DNA MTase [6,7]. By nomenclature Eco29kI RMS belongs to IIP group as one recognizing the palindromic site [4]. Its REase contains GIY-YIG nuclease domain that was identified in homing endonucleases, DNA repair and recombination enzymes, and restriction endonucleases [8,9]. Recently its mechanism of action was established: R.Eco29kI monomers dimerize on a single cognate DNA molecule forming the catalytically active complex [10]. An Eco29kI RMS is organized in such a way that REase ORF precedes MTase ORF, and the REase Stop codon and the MTase Start codon overlap (Figure 1A and 1B). Similar organization is also characteristic to such well-known RMS as SalI and HindIII. Using site-directed mutagenesis, eco29kI $R$ and $M$ ORFs were fused to give a fully functional hybrid protein. It was purified and characterized. Its biochemical properties, namely, REase and MTase specificities and the optima of reaction conditions were compared with those of the original enzymes.

Apparently, a similar mechanism of gene fusion via natural point mutations/deletions/insertions/invertions/ translocations could give type IIC REases as well as bifunctional MTases like SsoII-related enzymes and bifunctional MTases like FokI and LlaI [4,11,12]. Apart from methyltransferase, these proteins also possess separate domains involved in transcriptional regulation (SsoII) or methylation (FokI and LlaI). It should be noted that gene fusion is facilitated by the head-to-tail gene orientation, which is quite common for many RMS. For example, the following type II RM systems are organized in this way: AccI, BanI, Bsp6I, BsuBI, Cfr9I, DdeI, EagI, EcoPI, EcoP15, EcoRI, FnuDI, HaeIII, HgiBI, HgiCI, HgiCII, HgiDI, HgiEI, HgiGI, HhaII, HincII, HindIII, HinfI, HpaI, MboII, MwoI, NcoI, NdeI, NgoMI, NgoPII, NlaIII, PaeR7I, RsrI, SalI, Sau3A, Sau96I, TaqI, TthHB8I, XbaI, and XmaI, and many more can be found in RMS database $[3,12]$. Thus, their

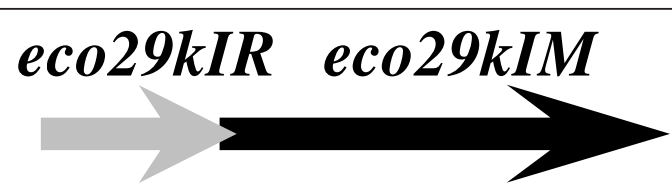

A

$$
\begin{aligned}
& \frac{\text { TAATG }}{\text { Stop Met }}=>\text { GGAGGG } \\
& \text { Gly Gly }
\end{aligned}
$$

B

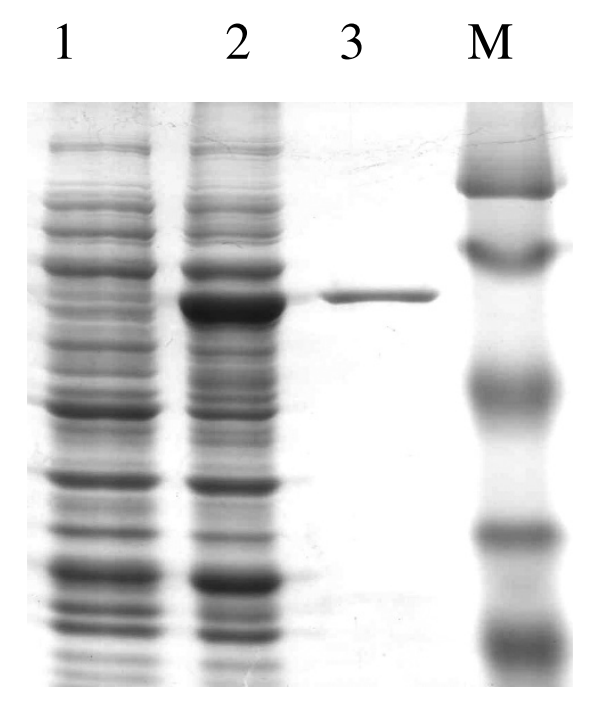

C

Figure 1 Overproducing strain construction and purification of protein RM.Eco29kl. A - eco29kIR and M ORFs orientation on the natural plasmid pECO29 [5]. On the plasmid Stop codon of eco29kIR gene overlaps Start codon of eco29k/M gene. B - A scheme of sitedirected mutagenesis used for generation of the fusion protein RM. Eco29kl. Overlapped Stop and Start codons were substitutes for two Glycine codons. C - 10\% PAGE electrophoresis with RM.Eco29kI induction (lane 2); final preparation of the enzyme (lane 3). Lane 1 protein extract from non-induced cells, M - Dalton markers of 26, $34,47,86$ and $120 \mathrm{kDA}$.

unidentified type IIC bifunctional derivatives could exist in nature.

\section{Results}

Construction of overproducing strain and purification of RM.Eco29kl

To construct an overproducing strain for the protein RM.Eco29kI, ORFs of Eco29kI REase and MTase were 
amplified from the natural plasmid pECO29 where they are oriented as shown in Figure 1A[5],. On this plasmid the Stop codon of Eco29kI REase and the Start codon of Eco29kI MTase overlap. Subsequently they were cloned in the same orientation into the pET19mod vector. By site-directed mutagenesis their separating Stop and Start codons were substituted for 2 Glycine codons, as shown in Figure 1B, thus forming the eco $29 k I . R M$ gene. The resulting RM.Eco29kI polypeptide contains both REase and MTase enzymes joint by a flexible 2 Glycine hinge and 6 His-tag on its $\mathrm{N}$ terminus.

The purification scheme for RM.Eco29kI was based on affinity (Ni-CAM, nickel chelate affinity matrix, Sigma) chromatography. From a Ni-CAM column RM.Eco29kI was eluted by linear steps of 20, 50, 75, 100 and 150 $\mathrm{mM}$ imidazole. Finally, $200 \mathrm{ml}$ of cell culture gave about $0.4 \mathrm{mg}$ of $>98 \%$ purified enzyme (Figure $1 \mathrm{C}$ ) with a molecular weight of $\sim 67 \mathrm{kDa}$.

When the Stop codon of Eco29kI REase gene was substituted for Glycine without modifying the first Methionine codon of Eco29kI MTase gene, expression of M. Eco29kI, but not RM.Eco29kI, was detected (unpublished observations). Hypothetically, it might happen due to a pronounced secondary structure of mRNA in the region corresponding to R.Eco29kI ORF or, as it was reported personally by $M$. Nagornykh, to transcription initiation from an alternative promoter closely preceding M.Eco29kI ORF [13].

\section{Characterization of RM.Eco29kl REase activity}

Two enzymes, R.Eco29kI and RM.Eco29kI, purified to homogeneity, were assayed for their recognition specificity and catalytic reaction optimum at varied concentrations of $\mathrm{NaCl}, \mathrm{KCl}$, temperature and $\mathrm{pH}$. R.Eco29kI was purified as described previously [14]. Figure 2 shows hydrolysis patterns of $\phi 80$ vir DNA with R.Eco29kI (lane 4) and with RM.Eco29kI (lane 3). The patterns are the same, so the hybrid protein RM.Eco $29 \mathrm{kI}$ retained the specificity of R.Eco29kI.

Then the enzyme RM.Eco29kI was assayed for catalytic reaction optimum. The maximal catalytic REase activity of the hybrid protein was observed at 0-50 mM $\mathrm{NaCl}$; 0-25 mM KCl, $10 \mathrm{mM} \mathrm{MgCl}_{2}$; $\mathrm{pH} 7.0$, at $30-37^{\circ} \mathrm{C}$ (Figure 3 and 4). Table 1 presents reaction optimum comparison for R.Eco29kI and RM.Eco29kI. As seen, the optima were slightly changed: $100 \mathrm{mM}$ less for $\mathrm{NaCl}, 50$ $\mathrm{mM}$ less for $\mathrm{KCl}$, and 1 unit less for $\mathrm{pH}$. It means that after fusion the biochemical properties of the REase part of the protein were changed, despite its intact amino acid sequence. Under optimal conditions R.Eco29kI had a specific activity of $60 \mathrm{AU} / \mathrm{pMol}$, whereas RM.Eco29kI had $20 \mathrm{AU} / \mathrm{pMol}$ amounting to $33 \%$ of the native value. Thus, after fusion with M.Eco29kI its activity was decreased by about 3 times.

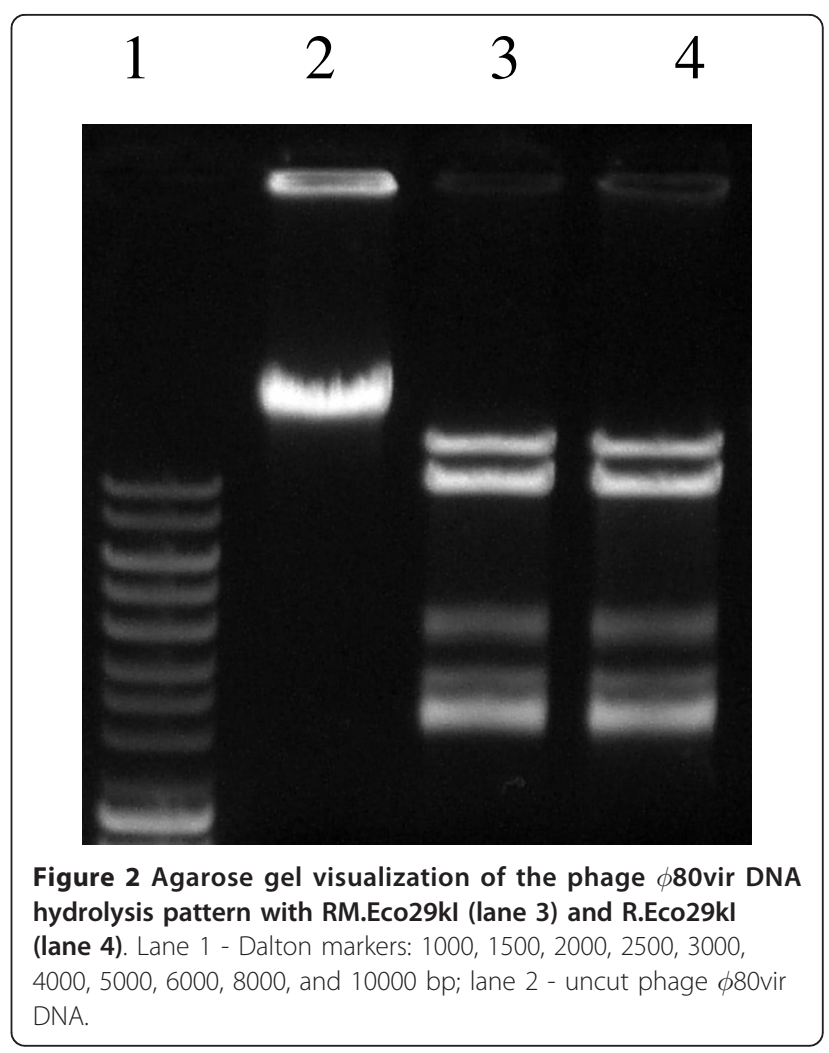

\section{Characterization of RM.Eco29kl MTase activity}

The biochemical characterization of Eco29kI MTase is presented in [15]. The enzyme methylates the second Cytosine in the sequence CC $^{\mathbf{M e}}$ GCGG. Specificity of RM.Eco29kI MTase activity was proved to be the same, because there was no incorporation of labeled methyl groups into substrates pretreated with M.Eco $29 \mathrm{kI}$ enzyme and non-labeled AdoMet. The optima of reaction conditions also remained unchanged: both enzymes showed their maximal activities at $50 \mathrm{mM} \mathrm{NaCl} ; 5 \mathrm{mM}$ EDTA; $\mathrm{pH} 7.0-8.5$, and $37^{\circ} \mathrm{C}$. Under optimal conditions M.Eco29kI had a specific activity of $10 \mathrm{AU} / \mathrm{pMol}$, whereas RM.Eco29kI had $8 \mathrm{AU} / \mathrm{pMol}$ amounting to $80 \%$ of the native value. Thus, after fusion with R.Eco29kI, activity of its MTase part was almost unchanged.

\section{Characterization of RM.Eco29kl functioning in vivo}

To characterize in vivo functioning of new RMS, we performed phage restriction experiments. In these experiments 100 -fold dilutions of phage $\lambda$ vir $\left(10^{0}, 10^{-2}\right.$, $\left.10^{-4}, 10^{-6}\right)$ were spotted on lawns of bacterial cells. The results are presented in Figure 5. BL21(DE3)xp29k11 cells carry only gene coding for Eco29kI MTase and lack Eco29kI REase activity, which allows evaluating total concentration of infective phage $\lambda$ vir virions. BL21 (DE3)xpECO29 cells carry natural pECO29 plasmid, having both MTase and REase activities of the wild type Eco29kI RMS. BL21(DE3)xpECO29RM cells carry gene 


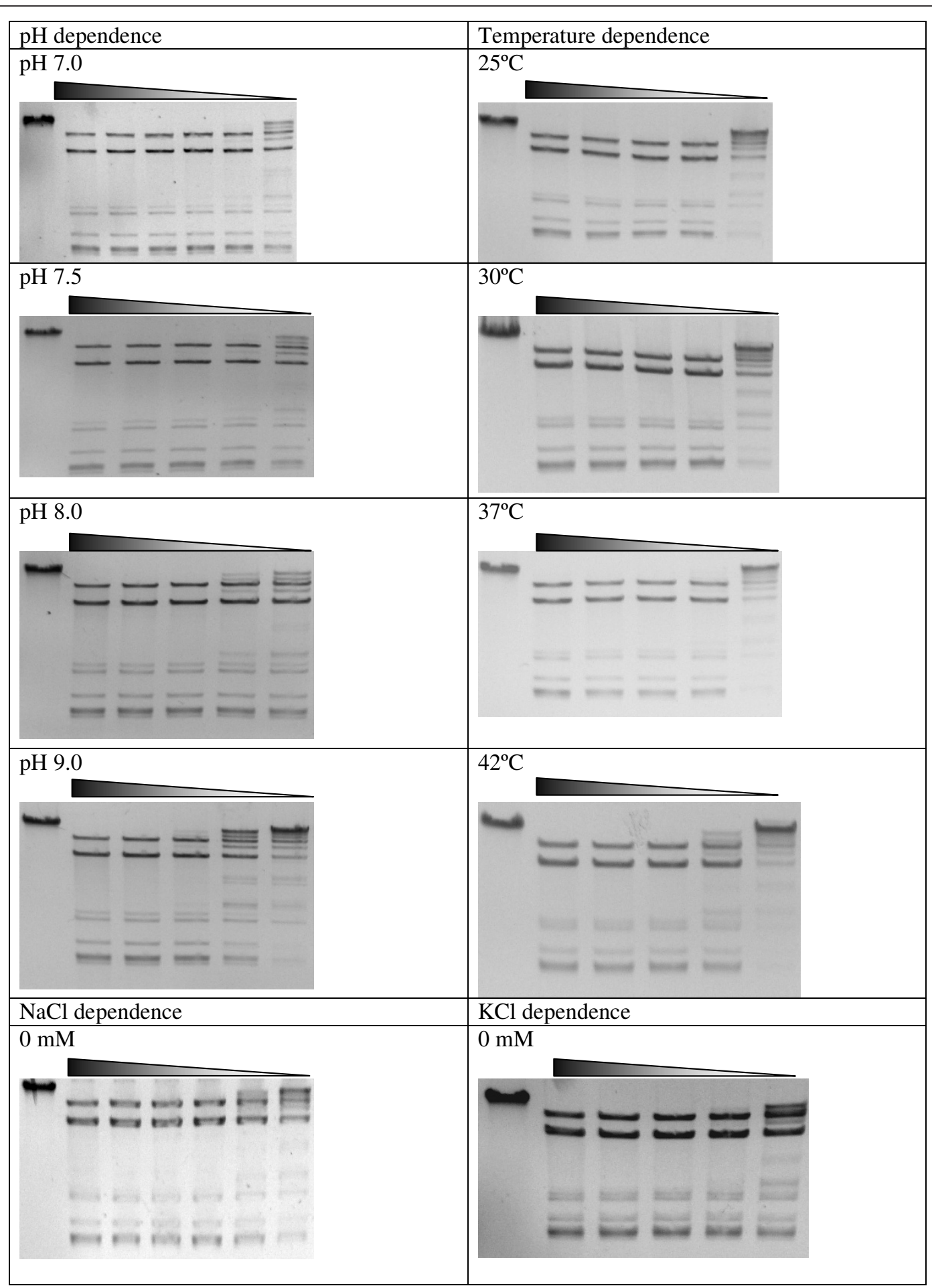

Figure 3 Reaction optima characterization for RM.Eco29kl. Triangles above gels mark 2-fold dilutions of the enzyme in the reaction mixtures. First lane of each gel represents uncut phage $\phi 80$ vir DNA. The gels represent RM.Eco29kl activity depending on $\mathrm{pH}$, temperature, $\mathrm{NaCl}$ and $\mathrm{KCl}$ concentrations. Varied parameters are written above each gel. 


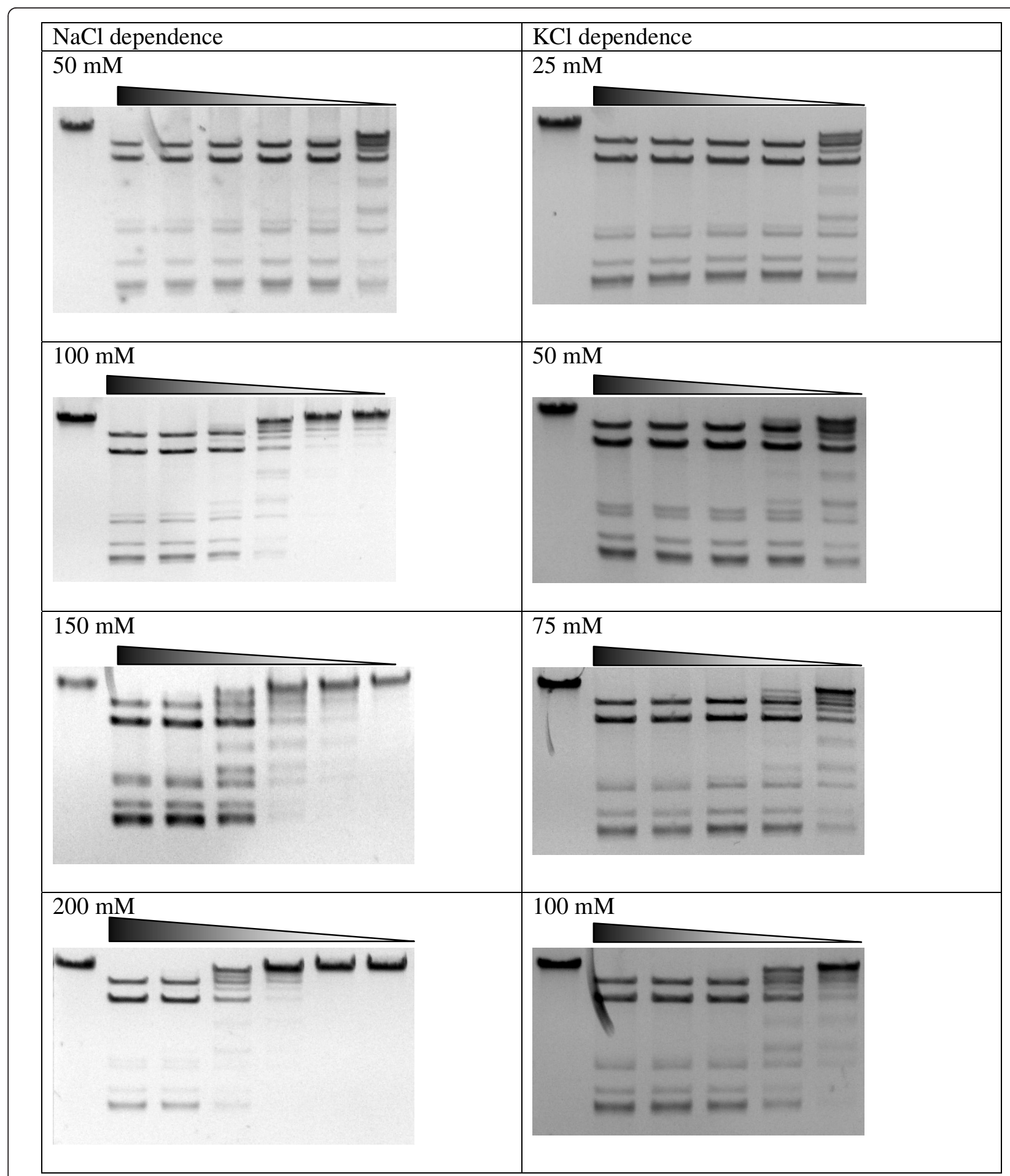

Figure 4 Reaction optima characterization for RM.Eco29kl, continuation of Figure 3.

coding for RM.Eco29kI enzyme on the natural pECO29 plasmid. BL21(DE3)xp29k11+p29RM cells carry genes coding for M.Eco29kI and RM.Eco29kI enzymes. As seen from the figure, RM.Eco29kI induction by low concentration of IPTG $(0.03 \mathrm{mM})$ led to a $10^{2}$-fold cell protection against phage invasions, so that only one out of 100 virions could infect the cells. The same values were obtained for RM.Eco29kI enzyme carried on natural pECO29 plasmid (pECO29RM variant). Under the given conditions wild type Eco29kI RMS protected cells 
Table 1 Comparison of reaction optima for R.Eco29kl and fused RM.Eco29kl

\begin{tabular}{ccc}
\hline & R.Eco29kl [14] & RM.Eco29kl \\
\hline$[\mathrm{NaCl}], \mathrm{mM}$ & $100-150$ & $0-50$ \\
{$[\mathrm{KCl}], \mathrm{mM}$} & $25-75$ & $0-25$ \\
$\mathrm{pH}$ & $7.0-8.0$ & 7.0 \\
$\mathrm{~T},{ }^{\circ} \mathrm{C}$ & $30-37$ & $30-37$ \\
\hline
\end{tabular}

more effectively, giving a $10^{4}$-fold restriction, so that only one out of 10, 000 virions could infect the cells. Thus, the new RMS protected its host cells $10^{2}$ times less effectively than the wild type RMS. But $10^{2}$ phage restriction value reflects the ability of the new RMS to protect cells against foreign DNA invasion; so this function of the wild type RMS was conserved in the RM. Eco29kI RMS.

\section{Characterization of RM.Eco29kl behavior in vitro}

To assess the in vitro interaction of the bifunctional enzyme RM.Eco29kI with DNA and the effect of AdoMet on its REase activity, we incubated this protein with phage $\phi 80 v i r$ DNA in conditions optimal for REase (Figure 6A) and MTase (Figure 6B) in the absence or presence of excess AdoMet $(10 \mu \mathrm{M})$. In MTase reaction mixture we substituted $5 \mathrm{mM}$ EDTA for $10 \mathrm{mM} \mathrm{MgCl}_{2}$ to supply magnesium ions to the REase part of the enzyme. While in REase buffer the hydrolysis patterns looked identical both in the presence and absence of AdoMet, in MTase buffer with AdoMet a slightly incomplete hydrolysis could be observed even at the lowest enzyme dilutions (Figure 6B), which could be explained by DNA methylation with the MTase part of the enzyme. It follows from these results that in vitro
RM.Eco29kI enzymatic reaction is strongly biased towards DNA hydrolysis, while only a small portion of DNA can be modified in the same reaction mixture; and that AdoMet does not influence REase activity of the enzyme, unlike other type IIC proteins known so far.

\section{Discussion}

\section{Nomenclature of the RM.Eco29kl enzyme}

To date, the following 12 proteins have been proved to show both REase and MTase activities by one polypeptide chain: AloI, BcgI, BseMII, BseRI, BsgI, BspLU11III, CjeI, Eco57I, HaeIV, MmeI, PpiI, and TstI [16-26]. They can be considered as members of the type IIC RMS group. Their properties are given in Table 2. All of them also belong to IIB (cutting on both sides of their recognition sequences) or to IIG (stimulated or inhibited with AdoMet) groups of RMS [4]. The RM.Eco29kI protein also falls in the category of IIC enzymes, but differs from its regular members by many features. It recognizes a true non-interrupted palindromic sequence; it cuts within the recognition site; its REase is not influenced by AdoMet; and its MTase belongs to $\mathrm{m}^{5} \mathrm{C}$ type, while others contain $\mathrm{m}^{6} \mathrm{~A}$ type MTases. Altogether, properties of RM.Eco29kI expand the limits of type IIC enzymes.

\section{The role of gene fusion in molecular evolution of RMS}

In our study a fully functional hybrid polypeptide was generated by fusion of Eco29kI REase and MTase proteins. New protein had REase and MTase specificities of the original enzymes. Its MTase activity was almost unchanged and amounted to $80 \%$ of that of the $M$. Eco29kI under optimal reaction conditions for both enzymes: $50 \mathrm{mM} \mathrm{NaCl} ; 5 \mathrm{mM}$ EDTA; $\mathrm{pH} 8.0$, and $37^{\circ} \mathrm{C}$

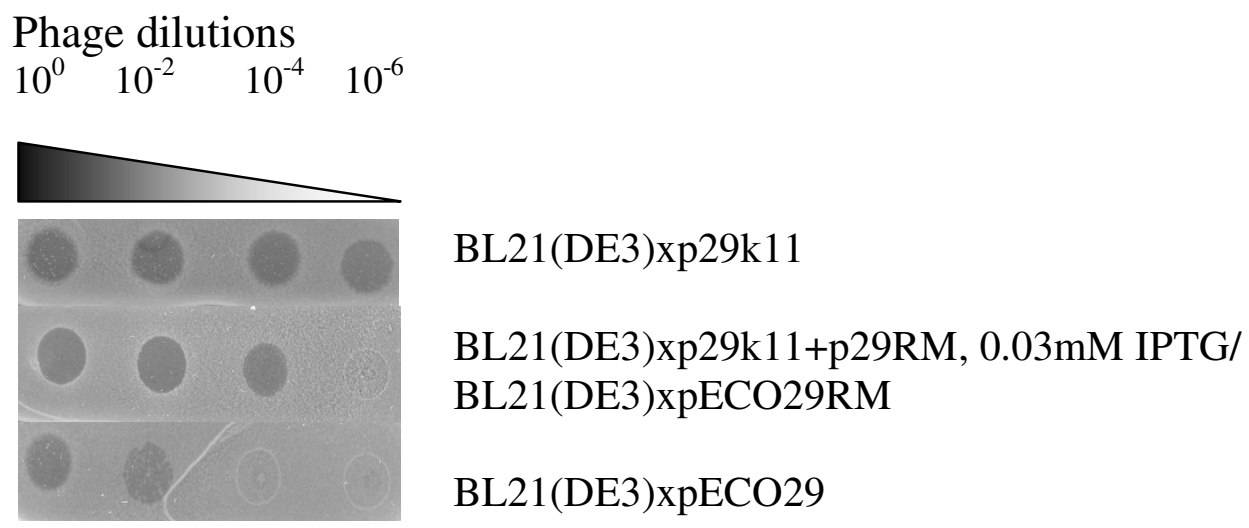

Figure 5 Phage restrictions by RM.Eco29k1. Triangle marks phage dilutions which are shown above. BL21(DE3)xp29k11 cells carry only gene coding for Eco29kl MTase and lack Eco29kl REase activity. BL21(DE3)xpECO29 cells carry natural pECO29 plasmid, having both MTase and REase activities of the wild type Eco29kl RMS. BL21(DE3)xp29k11+p29RM cells carry genes coding for M.Eco29kl and RM.Eco29kl enzymes on two different plasmids. 


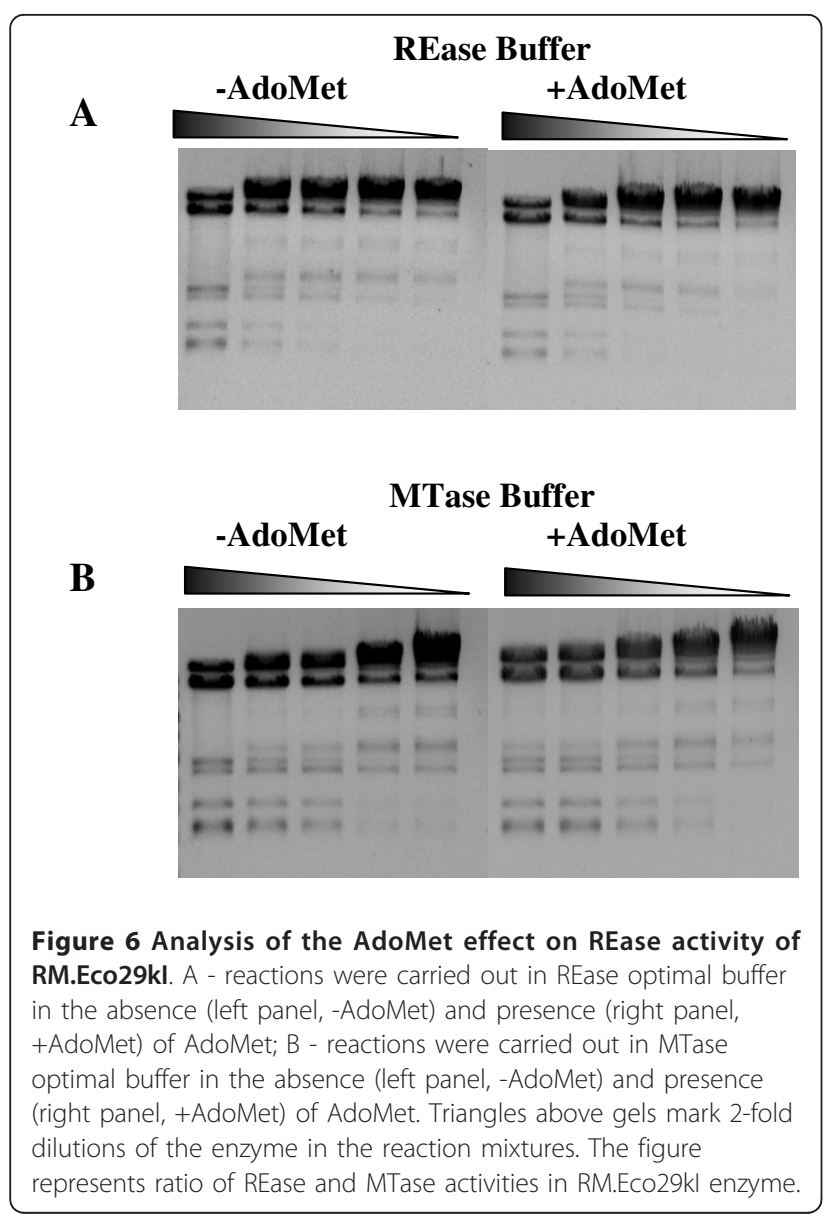

[15]. Its REase activity was decreased by three times, which could be attributed to increased steric hindrance in interaction with substrate. Besides, the reaction optimum for REase activity of RM.Eco29kI differed from that of the R.Eco29kI as follows: $100 \mathrm{mM}$ less for $[\mathrm{NaCl}], 50 \mathrm{mM}$ less for $[\mathrm{KCl}]$, and 1 unit less for $\mathrm{pH}$ (Table 1). The particular reason for this shift is unclear because many physical and chemical properties of the protein, such as molecular weight, isoelectric point, total charge, geometry of the protein, surface charge distribution, etc., were different from those of the original proteins. Hypothetically, the gap between their properties could yield as a result of the natural selection, after many generations, a novel protein with altered biochemical properties and different functions in the cell.

This work presents experimental evidence for molecular evolution of RMS or multifunctional proteins in general. It has been directly shown that a few point mutations can result in a protein with a novel combination of activities and altered properties. On the one hand, it may be considered as a molecular mechanism for appearance of type IIC RMS enzymes. Figure 7 and 8 show a schematic gene organization of the described type IIC RMS. As seen, all of them could result from fusion of head-to-tail oriented endonuclease and methyltransferase ORFs. Possible involvement of gene fusion was proposed for the formation of AloI, BseMII, CjeI, Eco57I, HaeIV, and MmeI. The enzymes AloI, CjeI, and HaeIV probably resulted from fusion of HsdS, HsdM and REase domains; Eco57I - from Mod and Res subunits of type III enzymes; while BseMII and MmeI - from REase and MTase domains [16,18,23,25].

It can be predicted that novel type IIC RMS may appear via fusion of genes from bipartite RMS having head-to-tail gene organization. This type of gene organization is quite common for RMS of all types. Type I RMS such as CfrA, EcoA, EcoB, EcoD, EcoE, EcoK,

Table 2 Major properties of proved type IIC enzymes

\begin{tabular}{|c|c|c|c|c|c|}
\hline Enzyme & $\begin{array}{l}\text { Other } \\
\text { subtypes }\end{array}$ & Recognition sequence & $\begin{array}{l}\text { AdoMet influence } \\
\text { on REase }\end{array}$ & Type of MTase & Presence of separate $M$ gene \\
\hline Alol [16] & $B, G, S$ & $\begin{array}{c}\text { (7/12-13) GAACNNNNNNTCC } \\
(12-13 / 7)\end{array}$ & yes & $\mathrm{m}^{6} \mathrm{~A}$ & no \\
\hline Bcgl [17] & $B, G, H, S$ & (10/12) CGANNNNNNTGC (12/10) & yes & $m^{6} \mathrm{~A}$ & no \\
\hline BseMII [18] & $G, S$ & CTCAG (10/8) & yes & $m^{6} \mathrm{~A}$ & yes \\
\hline BseRI [19] & $G, S$ & GAGGAG (10/8) & yes & $m^{6} \mathrm{~A}$ & no \\
\hline Bsgl [20] & $\mathrm{G}, \mathrm{S}$ & GTGCAG (16/14) & yes & $\mathrm{m}^{6} \mathrm{~A}$ & no \\
\hline $\begin{array}{c}\text { BspLU11III } \\
{[21]}\end{array}$ & $\mathrm{G}, \mathrm{S}$ & GGGAC (10/14) & yes & $\mathrm{m}^{6} \mathrm{~A}$ & yes, two genes \\
\hline Cjel [22] & $B, G, S$ & (8/14) CCANNNNNNGT (15/9) & yes & $\mathrm{m}^{6} \mathrm{~A}$ & no \\
\hline $\begin{array}{l}\text { RM.Eco29kl } \\
\text { This report }\end{array}$ & $P$ & $C C G C \wedge G G$ & no & $m^{5} \mathrm{C}$ & yes \\
\hline Eco57l [23] & $E, G, S$ & CTGAAG (16/14) & yes & $m^{6} \mathrm{~A}$ & yes \\
\hline HaelV [24] & $B, G, P$ & (7/13) GAYNNNNNRTC (14/9) & yes & $\mathrm{m}^{6} \mathrm{~A}$ & no \\
\hline Mmel [25] & $G, S$ & TCCRAC (20/18) or TCCRAC (21/19) & yes & $\mathrm{m}^{6} \mathrm{~A}$ & no \\
\hline Ppil [26] & $B, G, S$ & (7/12) GAACNNNNNCTC (13/8) & yes & $\mathrm{m}^{6} \mathrm{~A}$ & no \\
\hline Tstl [26] & $B, G, S$ & (8/13) CACNNNNNNTCC (12/7) & yes & $\mathrm{m}^{6} \mathrm{~A}$ & no \\
\hline
\end{tabular}






EcoR124, StySB, StySI, StySP, and StySQ; type II RMS such as AccI, BanI, Bsp6I, BsuBI, Cfr9I, DdeI, EagI, EcoPI, EcoP15, EcoRI, FnuDI, HaeIII, HgiBI, HgiCI, HgiCII, HgiDI, HgiEI, HgiGI, HhaII, HincII, HindIII, HinfI, HpaI, MboII, MwoI, NcoI, NdeI, NgoMI, NgoPII, NlaIII, PaeR7I, RsrI, SalI, Sau3A, Sau96I, TaqI, TthHB8I, $\mathrm{XbaI}$, and XmaI, all have head-to-tail gene orientation, thus being good candidates for originating new type IIC enzymes [12]. These possibilities could be facilitated by increased affinity of DNA MTases for hemimethylated substrates in comparison with non-methylated ones, unlike their REase counterparts. Therefore, if a fused RMS appeared from preexisting bipartite RMS and its MTase activity was lower of the original enzyme, its propagation would be facilitated by facts that all recognition sites in the host genome were methylated or, after replication, hemimethylated by the preexisting enzyme and that it had increased affinity to hemimethylated substrates. Otherwise, decreased MTase activity of a new fused RMS could lead to appearance of unprotected recognition sequences in host genome, which will be cut by REase, host cells will die and this RMS will not propagate in a bacterial population.

On the other hand, this study provides an example of a more general mechanism for gaining new functions by existing proteins. Hypothetically, any pair of ORFs can be joint in-frame by point mutations/deletions/insertions/inversions/translocations or their combinations (Figure 9). Then the newly generated polypeptide may serve as an evolutionary intermediate for the natural selection in improving old or accommodating new functions in the cell. For example, M.SsoII-related bifunctional enzymes, including its izoschizomers, with regulatory and MTase domains could arise by natural fusion of the appropriate ORFs at some stages of their evolutionary history $[11,27]$. The latter suggestion is supported by the presence of NlaX MTase, a close homolog of M.SsoII without the regulatory N-terminal domain. As shown in Figure 10, both polypeptides display high identity after 70 amino acids of the M.SsoII $\mathrm{N}$-terminal domain known to be involved in its gene autoregulation [11]. Similar fusion of preexisting headto-tail oriented ORFs coding for C-protein and endonuclease in BamHI, Eco72I, MunI, PvuII, SmaI RMS, could give REases with transcription regulatory functions. Depending on gene organization, there are also possibilities for fusion of two MTases from preexisting RMS, such as DpnII and HgaI, leading to bifunctional MTases like FokI and LlaI [12].

In principle, any other adjacent gene of appropriate orientation could be fused with the REase or MTase part of RMS. In this case the fact that RMS elimination is lethal for cells would defend the fused ORF from being lost [28]. It occurs because long-lasting endonucleolitic activity results in multiple cuts on non-protected genomic DNA, thereby killing cells that lack RMS. Thus, joining RMS genes would promote maintenance of a fused ORF and its spreading in bacterial populations, provided their functioning is not disturbed.

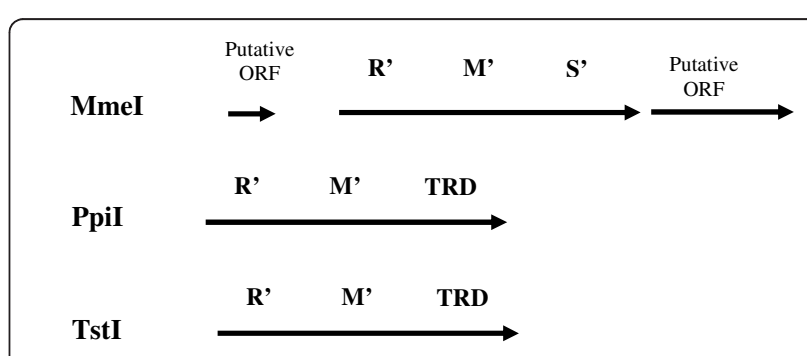

Figure 8 Organization schemes of proved type IIC RMS, continuation of Figure 7 . 


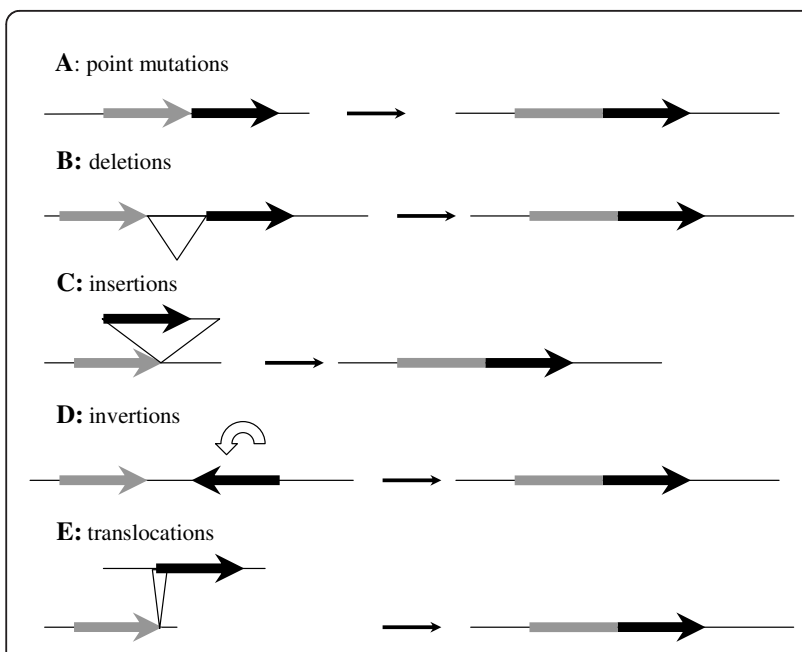

Figure 9 A scheme of genetic rearrangement events that could lead to single ORF fusions. Grey and black arrows show any hypothetical ORFs; white circle arrow - inversion of DNA; triangles recombination between different pieces of DNA. On the figure are shown genetic pathways that could lead to gene fusion.

\section{Practical applications of gene fusion for generating REases with novel recognition sites}

Restriction enzymes are robust tools for the recombinant DNA technology. Despite the fact that more than 200 enzymes with different recognition sites have been isolated from various bacterial strains, many specificities have not been discovered $[23,26]$. To create enzymes with altered recognition specificities, methylation activity-based selection (MABS) and target recognition domain (TRD) reassortment $[23,26]$ approaches were proposed. Using these techniques, bifunctional enzymes of type IIC such as Eco57I, AloI, Ppil, and TstI were manipulated to yield a generation with novel specificities. Most importantly, both of their activities operated on the same target sequence, thus providing a possibility to use the DNA-modification activity of these enzymes for the selection of mutants with altered sequence specificity. To enlarge the list of enzymes available for these manipulations, a gene fusion approach, similar to one used in this work, could be applied. By this procedure, hundreds of bifunctional enzymes could be created, e.g., from type I and III head-to-tail oriented RMS, thus giving an opportunity of significant contribution to the existing recognition specificities.

\section{Conclusions}

Altogether, our work presents an example of molecular mechanism for appearance of type IIC restriction-modification and SsoII MTase-related enzymes as well as other multifunctional proteins. It demonstrates that gene fusion could play an important role in evolution of restriction- modification systems and be responsible for enzyme subclass interconversion. Based on the proposed approach, hundreds of novel type IIC enzymes could be generated from head-to-tail oriented type I, II and III restriction and modification genes. These new bifunctional polypeptides could be useful for creating enzymes with altered recognition specificities. Lastly, our work shows that protein fusion can change biochemical properties of the involved enzymes, thus giving a starting point for their further evolutionary divergence, which, after many generations, gives a novel protein with both altered biochemical properties and different functions in the cell.

\section{Methods}

\section{Bacterial Culture}

All strains used were grown in LB liquid medium with high aeration. For selection ampicillin $(100 \mu \mathrm{g} / \mathrm{ml})$ and kanamycin $(25 \mu \mathrm{g} / \mathrm{ml})$ were added to LB agar plates [29].

\section{DNA Manipulations}

All genetic engineering methods were performed as described [29]. Selection of transformants with plasmids carrying Eco29kI RMS genes and screening of recombinant clones were performed as elsewhere [30,31].

\section{Chemicals, Bacterial Strains, Plasmids and Enzymes}

E. coli BL21(DE3) (Novagen) and Z-85 strains were used for transformation experiments [32]. Plasmids pET19mod, pECO29, and p29k11 were used for a number of experiments $[5,7,33]$. Restriction endonucleases, T4 DNA ligase, and thermostable DNA-polymerase from Th. aquaticus were purified in our laboratory. Pfu DNA polymerase was purchased from New England Biolabs (UK). Protein and DNA ladders were obtained from Fermentas (Lithuania).

Strain BL21(DE3) (Novagen), transformed with plasmid p29k11 $\left(\mathrm{Km}^{\mathrm{r}}\right)$ bearing eco29kIM gene was used as a host for transformation of plasmid containing eco $29 \mathrm{kI}$ $R M$ fusion gene [7].

$\left({ }^{3} \mathrm{H}\right.$-methyl)-labeled AdoMet $(15 \mathrm{Ci} / \mathrm{mMol})$ was purchased from Amersham Biosciences; unlabeled AdoMet, potassium phosphate, sodium chloride, potassium chloride, bovine serum albumin were from Sigma. Acrylamide, methylenebisacrylamide, Coomassie Brilliant Blue R-250 and Low Melting Agarose (LMP) were from BioRad. All other chemical reagents used were of the highest grade purity.

\section{Construction of Eco29kl REase and MTase fusion RM. Eco29kl protein overproducing strain and biomass production}

Eco29kI REase and MTase genes were amplified from the natural plasmid pECO29 with primers 


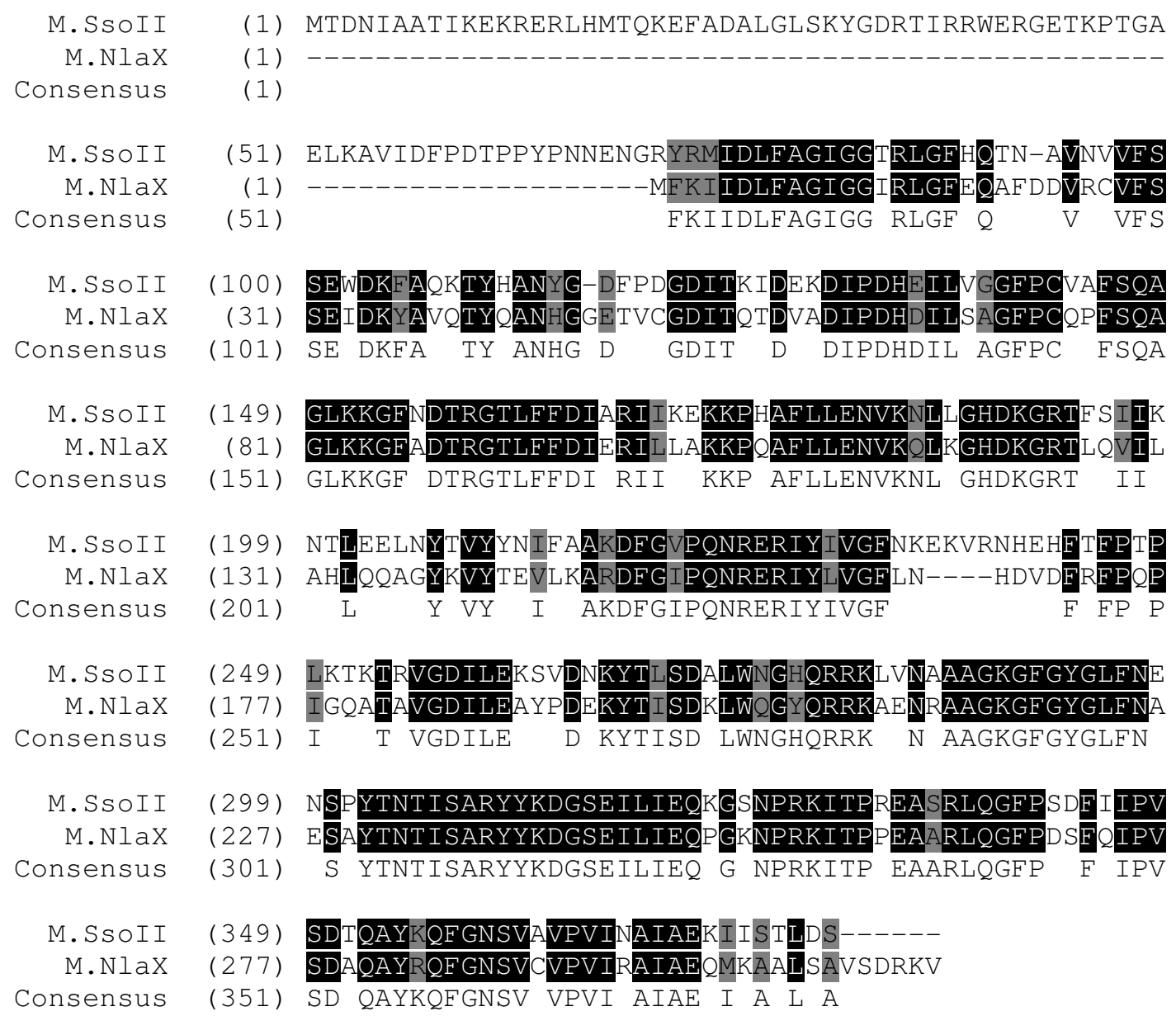

Consensus

Figure 10 A scheme of alignment for M.Ssoll and M.NlaX. Identical amino acids are marked by black and similar amino acids by grey background. The figure demonstrates presence of 70 aa N-terminal domain in M.Ssoll, but not in M.NlaX.

TTTGTCGACATGCACAATAAGAAATTTGATA (forward; containing start ATG codon shown in bold) and CCTGGATCCCTTTTAATTGAAGTTAGAGCACAA (reverse; containing stop TTA codon shown in bold), carrying SalI and BamHI sites, respectively, for subsequent cloning [5]. Appropriately digested PCR product was cloned into pET19mod vector. Site-directed mutagenesis has been performed to fuse Eco29kI REase and MTase ORFs, using the high fidelity Pfu DNA polymerase and oligonucleotide primers:

Fus1: AAGAGTAATTTTACAGGAGGGAGATCATTAGAG and

Fus2:

\section{CTCTAATGATCTCCCTCCTGTAAAATTACTCTT.}

A novel plasmid containing staggered nicks was generated. Following the thermal cycling, the reaction mixture was treated with DpnI REase that digests hemimethylated parental DNA, leaving behind the newly amplified nicked DNA with the mutation of interest. The mutation and
eco29kI.RM gene were confirmed by sequencing. The resulting construct was referred to as $\mathrm{p} 29 \mathrm{RM}$.

The plasmid p29RM was introduced into E. coli BL21 (DE3) strain. Cells were grown in LB medium supplemented with ampicillin and kanamycin at $20^{\circ} \mathrm{C}$. After reaching $\mathrm{OD}_{590}=0.6$, the recombinant protein $\mathrm{RM}$. Eco29kI synthesis was induced by addition of isopropyl$\beta$-D-thiogalactopyranoside (IPTG) to a final concentration of $0.1 \mathrm{mM}$ followed by overnight incubation at $20^{\circ} \mathrm{C}$. Cells were harvested by centrifugation, frozen and stored at $-70^{\circ} \mathrm{C}$. All subsequent steps were carried out at $4^{\circ} \mathrm{C}$.

\section{Construction of natural pECO29 plasmid carrying fused Eco29kl REase and MTase genes}

To make Eco29kI REase and MTase gene fusion on natural pECO29 plasmid, its BclI-PvuII fragment was substituted for BclI-PvuII fragment of p29RM plasmid, containing the gene fusion mutations. Resulting plasmid was referred as pECO29RM. 


\section{Protein Purification}

RM.Eco29kI-producing E.coli cells pelleted from 200 $\mathrm{ml}$ of culture were lysed by lysozyme treatment $(1 \mathrm{mg} /$ $\mathrm{ml}, 30 \mathrm{~min}$ at $4^{\circ} \mathrm{C}$ ) in $5 \mathrm{ml}$ of ice-cold buffer $\mathrm{A}$ (50 mM Tris- $\mathrm{mCl}, \mathrm{pH} 7.5,300 \mathrm{mM} \mathrm{NaCl}, 5 \mathrm{mM}$ $\beta$-mercaptoethanol, $10 \mathrm{mM}$ Imidazole, and $5 \%$ glycerol $(\mathrm{v} / \mathrm{v})$ ) with protease inhibitor $1 \mathrm{mM}$ phenylmethylsulfonyl fluoride (PMSF), followed by sonication. Triton X100 was added to the lysate to a final concentration of $1 \%$, and the lysate was subjected to centrifugation at $14,000 \mathrm{rpm}, 4^{\circ} \mathrm{C}$ for $40 \mathrm{~min}$ to eliminate cell debris. The resulting supernatant was applied to a Ni-CAM (Sigma) column equilibrated with buffer A with $1 \%$ Triton X-100. After washing the column with buffer B (50 mM Tris- $\mathrm{HCl}, \mathrm{pH} 7.5,1 \mathrm{M} \mathrm{NaCl}, 5 \mathrm{mM} \beta$-mercaptoethanol, $15 \mathrm{mM}$ Imidazole, $5 \%$ glycerol (v/v), and $1 \%$ Triton $\mathrm{X}-100)$, the protein was eluted using linear steps (20-150 mM) of imidazole in buffer A with $0.1 \%$ Triton X-100. Active fractions with specific REase activity containing homogenous RM.Eco29kI (as judged by SDS-PAGE) were pooled and dialyzed overnight against storage buffer $(50 \mathrm{mM}$ Tris- $\mathrm{HCl}, \mathrm{pH} 7.5$, $250 \mathrm{mM} \mathrm{NaCl}, 7 \mathrm{mM} \beta$-mercaptoethanol, $0.1 \mathrm{mM}$ EDTA, $0.1 \%$ Triton X-100, 50\% glycerol (v/v)) and stored at $-20^{\circ} \mathrm{C}$. The purified protein was analyzed by SDS-PAGE according to the method of Laemmli using Coumassie Blue R-250 (BioRad, USA) conventional staining [34].

\section{Characterization of phage restriction by RM.Eco29kl RMS}

To characterize RM.Eco29kI RMS ability to protect host cells against phage invasion different dilutions of phage $\lambda$ vir $\left(10^{0}, 10^{-2}, 10^{-4}, 10^{-6}\right)$ were spotted on bacterial lawns of BL21(DE3)xp29k11 (negative control), BL21 (DE3)xp29k11+p29RM (with 0.03 mM IPTG), BL21 (DE3)xpECO29RM (eco29kIRM gene under natural promoter) and BL21(DE3)xpECO29 (positive control) cells. Then minimal concentrations of phage $\lambda$ vir, capable to infect corresponding strains, were compared.

\section{Methylation Assay}

To test RM.Eco29kI DNA methyltransferase activity, we used DE-filters assay according to [35].

\section{Analysis of Protein Concentration}

Protein concentration was determined from the absorption at $280 \mathrm{~nm}$ on a Shimadzu UV-1601 spectrophotometer (Japan). An extinction coefficient was calculated by ProtParam tool http://www.expasy.ch: $94240 \mathrm{M}^{-1} \mathrm{~cm}^{-1}$.

\section{RM.Eco29kl REase- and MTase reaction optima}

Optimum conditions for endonuclease and methyltransferase reactions of RM.Eco29kI were studied as before $[14,15]$.

\section{Investigation of AdoMet influence on REase activity of RM.Eco29kl}

To study the AdoMet effect on REase activity of RM. Eco29kI, $0.5 \mu \mathrm{g}$ of phage $\phi 80 \mathrm{vir}$ DNA was treated with 2-fold dilutions of $0.1 \mu \mathrm{g}$ RM.Eco29kI at REase $(50 \mathrm{mM}$ $\mathrm{NaCl}, 10 \mathrm{mM} \mathrm{MgCl}$; $20 \mathrm{mM}$ Tris- $\mathrm{HCl}, \mathrm{pH} 7.5)$ and MTase $(50 \mathrm{mM} \mathrm{NaCl} ; 5 \mathrm{mM} \beta$-mercaptoethanol; 20 $\mathrm{mM}$ Tris- $\mathrm{HCl}, \mathrm{pH} 8.0$, with $10 \mathrm{mM} \mathrm{MgCl}_{2}$ ) optimal conditions with or without excess AdoMet $(10 \mu \mathrm{M})$ for $1 \mathrm{~h}$ at $37^{\circ} \mathrm{C}$. Reaction products were analyzed electrophoretically in $0.8 \%$ agarose gel.

\section{Unit definition}

The amount of enzyme required to transfer 1 pmol of $\left({ }^{3} \mathrm{H}\right)$-methyl groups to DNA per minute with saturating concentrations of substrates at $37^{\circ} \mathrm{C}$ has been taken as 1 AU of the RM.Eco29kI DNA methyltransferase activity. The amount of enzyme required to cut $1 \mu \mathrm{g}$ of phage $\phi 80$ vir DNA during $1 \mathrm{~h}$ at $37^{\circ} \mathrm{C}$ has been taken as $1 \mathrm{AU}$ of the RM.Eco29kI restriction endonuclease activity. Both reactions were carried out under predefined optimal reaction conditions.

List of abbreviations used

ORF: open reading frame; REase: restriction endonuclease; MTase: methyltransferase; RMS: restriction-modification system; AdoMet: S-adenosylL-methionine; TRD: target recognition domain; R.Eco29kl: REase Eco29kl; M. Eco29kl: MTase Eco29kl; RM.Eco29kl: fused REase and MTase Eco29kl in one polypeptide; Aa: amino acids; bp: base pairs; 6 His: 6 Histidine residues; LB medium: Luria-Bertani medium; Rpm: rotations per minute; EDTA: ethylenediaminetetraacetic acid; DTT: dithiothreitol; PAGE: polyacrylamide gel electrophoresis; AU: arbitrary units; pMol: $10^{-12} \mathrm{Mol}$; $\mu \mathrm{g}: 10^{-6} \mathrm{~g}$.

\section{Acknowledgements}

The authors thank Prof. E.S. Gromova and N.A. Cherepanova for help in MTase activity characterization experiments and Dr. M.V. Zakharova for the kindly provided plasmid p29K11. DN's work on this project was supported by a Russian Science Support Foundation award.

\section{Author details}

${ }^{1}$ Institute of Biochemistry and Physiology of Microorganisms, Russian Academy of Sciences, Prospekt Nauki, 5, Pushchino, Moscow region 142290, Russia. ${ }^{2}$ Pushchino State University, Prospekt Nauki, 3, Pushchino, Moscow region 142290, Russia.

\section{Authors' contributions}

DN and AS designed experiments; MM and DN performed experiments; DN wrote the paper. MM, AS and DN read and approved the final manuscript.

Received: 3 August 2009 Accepted: 3 February 2011

Published: 3 February 2011

\section{References}

1. Williams RJ: Restriction endonucleases: classification, properties, and applications. Mol Biotechnol 2003, 23:225-243.

2. Skowronek KJ, Bujnicki JM: In Industrial Enzymes: Structure, Function and Applications. Volume Chapter 21. Edited by: Polaina J, MacCabe AP. Springer; 2007.

3. Roberts RJ, Vincze T, Posfai J, Macelis D: REBASE-a database for DNA restriction and modification: enzymes, genes and genomes. Nucl Acids Res 2010, 38:234-236.

4. Roberts RJ, Belfort M, Bestor T, Bhagwat AS, Bickle TA, Bitinaite J, Blumenthal RM, Degtyarev S, Dryden DT, Dybvig K, et al: A nomenclature 
for restriction enzymes, DNA methyltransferases, homing endonucleases and their genes. Nucleic Acids Res 2003, 31:1805-1812.

5. Pertzev A, Ruban N, Zakharova M, Beletzkaja I, Petrov S, Kravetz A Solonin A: Eco29kl, a novel plasmid encoded restriction endonuclease from Escherichia coli. Nucleic Acids Res 1992, 20:1991.

6. Zakharova M, Pertzev A, Kravetz A, Beletskaya I, Shlyapnikov M, Solonin A: Complete nucleotide sequence of the Hsd plasmid pECO29 and identification of its functional regions. Bioch Bioph Acta 1998, 1398:106-112.

7. Zakharova M, Beletskaya I, Kravetz A, Pertzev A, Mayorov S, Shlyapnikov M, Solonin A: Cloning and sequence analysis of the plasmid-borne genes encoding the Eco29kl restriction and modification enzymes. Gene 1998, 208:177-182.

8. Bujnicki J, Radlinska M, Rychlewski L: Polyphyletic evolution of type II restriction enzymes revisited: two independent sources of second-hand folds revealed. TREND in Biochemical Sciences 2001, 26:9-11.

9. Ibryashkina E, Zakharova M, Baskunov V, Bogdanova E, Nagornykh M, Den'mukhamedov M, Melnik B, Kolinski A, Gront D, Feder M, Solonin A, Bujnicki J: Type II restriction endonuclease R.Eco29kl is a member of the GIY-YIG nuclease superfamily. BMC Struct Biol 2007, 7:48.

10. Ibryashkina M, Sasnauskas G, Solonin A, Zakharova M, Siksnys V: Oligomeric structure diversity within the GIY-YIG nuclease family. J Mol Biol 2009, 387:10-16.

11. Karyagina A, Shilov I, Tashlitskii V, Khodoun M, Vasil'ev S, Lau P, Nikolskaya I: Specific binding of Ssoll DNA methyltransferase to its promoter region provides the regulation of Ssoll restriction-modification gene expression. Nucleic Acids Res 1997, 25:2114-2120.

12. Wilson GG: Organization of restriction-modification systems. Nucleic Acids Res 1991, 19:2539-2566.

13. Nagornykh M: Regulation of expression of Eco29kl restrictionmodification system. PhD thesis Institute of Biochemistry and Physiology of Microorganisms RAS. Molecular Biology department; 2010.

14. Nikitin D, Mokrishcheva M, Denjmukhametov M, Pertzev A, Zakharova M, Solonin A: Construction of an overproducing strain, purification, and biochemical characterization of the $6 \mathrm{His}$-Eco29kl restriction endonuclease. Protein Expr Purif 2003, 30:26-31.

15. Nikitin D, Mokrishcheva M, Solonin A: 6His-Eco29kl methyltransferase methylation site and kinetic mechanism characterization. Biochim Biophys. Acta 2007, 1774:1014-1019.

16. Cesnaviciene E, Petrusiyte M, Kazlauskiene R, Maneliene Z, Timinskas A, Lubys A, Janulaitis A: Characterization of Alol, a Restriction-modification System of a New Type. J Mol Bio 2001, 314:205-216.

17. Kong H, Roemer S, Waite-Rees P, Benner J, Wilson G, Nwankwo D: Characterization of Bcgl, a New Kind of Restriction-Modification System. J Biol Chem 1994, 269:683-690.

18. Jurenaite-Urbanaviciene S, Kazlauskiene R, Urbelyte V, Maneliene Z, Petrusyte M, Lubys A, Janulaitis A: Characterization of BseMII, a new type IV restriction-modification system, which recognizes the pentanucleotide sequence 5'-CTCAG(N)(10/8)/. Nucleic Acids Re 2001, 29:895-903.

19. Mushtaq R, Naeem S, Sohail A, Riazuddin S: BseRI a novel restriction endonuclease from a Bacillus species which recognizes the sequence 5'...GAGGAG...3'. Nucleic Acids Res 1993, 21:3585.

20. Gemmen G, Millin R, Smith D: DNA looping by two-site restriction endonucleases: heterogeneous probability distributions for loop size and unbinding force. Nucleic Acids Res 2006, 34:2864-2877.

21. Lepikhov K, Tchernov A, Zheleznaja L, Matvienko N, Walter J, Trautner TA: Characterization of the type IV restriction modification system BspLU11III from Bacillus sp. LU11. Nucleic Acids Res 2001, 29:4691-4698

22. Vitor J, Morgan R: Two novel restriction endonucleases from Campylobacter jejuni. Gene 1995, 157:109-110.

23. Rimseliene R, Maneliene Z, Lubys A, Janulaitis A: Engineering of restriction endonucleases: using methylation activity of the bifunctional endonuclease Eco57l to select the mutant with a novel sequence specificity. J Mol Biol 2003, 327:383-391.

24. Piekarowicz A, Golaszewska M, Sunday A, Siwińska M, Stein D: The HaelV restriction modification system of Haemophilus aegyptius is encoded by a single polypeptide. J Mol Biol 1999, 293:1055-1065

25. Nakonieczna J, Kaczorowski T, Obarska-Kosinska A, Bujnicki JM: Functional analysis of Mmel from methanol utilizer Methylophilus methylotrophus, a subtype IIC restriction-modification enzyme related to type I enzymes. Appl Environ Microbiol 2009, 75:212-223.

26. Jurenaite-Urbanaviciene S, Serksnaite J, Kriukiene E, Giedriene J, Venclovas C, Lubys A: Generation of DNA cleavage specificities of type II restriction endonucleases by reassortment of target recognition domains. PNAS 2007, 104:10358-10363.

27. Denjmukhametov M, Brevnov M, Zakharova M, Repyk A, Solonin A, Petrauskene O, Gromova E: The Ecl18kl restriction-modification system: cloning, expression, properties of the purified enzymes. FEBS Lett 1998, 433:233-236

28. Kobayashi I, Nobusato A, Kobayashi-Takahashi N, Uchiyama I: Shaping the genome-restriction-modification systems as mobile genetic elements. Curr Opin Genet Dev 1999, 9:649-656.

29. Sambrook J, Fitsch EF, Maniatis T: Molecular Cloning: A Laboratory Manual Cold Spring Harbor, Cold Spring Harbor Press; 1989.

30. Bougueleret L, Schwarzstein M, Tzugita A, Zabeau M: Characterization of the genes coding for the Eco RV restriction and modification system of Escherichia coli. Nucleic Acids Res 1984, 12:3659-3676.

31. Lunnen K, Barsomian J, Camp R, Card C, Chen S, Croft R, Looney M, Meda M, Moran L, Nwankwo D, et al: Cloning type-II restriction and modification genes. Gene 1988, 74:25-32.

32. Zaitzev E, Zaitzeva E, Bakhlamova I, Gorelov V, Kuzmin N, Kryukov V, Lanzov V: Cloning and characterization of rec A gene from Pseudomonas aeruginosa. Genetika (Russian) 1986, 22:2721-2727.

33. Alexandrov K, Simon I, Yurchenko V, lakovenko A, Rostkova E, Scheidig AJ, Goody RS: Characterization of the ternary complex between Rab7, REP-1 and Rab geranylgeranyl transferase. Eur J Biochem 1999, 265:160-170.

34. Laemmli U: Cleavage of structural proteins during the assembly of the head of bacteriophage T4. Nature 1970, 227:680-685.

35. Rubin R, Modrich P: EcoRI methylase. Physical and catalytic properties of the homogeneous enzyme. J Biol Chem 1977, 252:7265-7272.

doi:10.1186/1471-2148-11-35

Cite this article as: Mokrishcheva et al:: Fused eco29kIR- and $M$ genes coding for a fully functional hybrid polypeptide as a model of molecular evolution of restriction-modification systems. BMC Evolutionary Biology 2011 11:35.

\section{Submit your next manuscript to BioMed Central and take full advantage of:}

- Convenient online submission

- Thorough peer review

- No space constraints or color figure charges

- Immediate publication on acceptance

- Inclusion in PubMed, CAS, Scopus and Google Scholar

- Research which is freely available for redistribution

Submit your manuscript at www.biomedcentral.com/submit
Ciomed Central 